\title{
The Primary Care Respiratory Society-UK Quality Award: development and piloting of quality standards for primary care respiratory medicine
}

\author{
*Kevin Gruffydd-Jones', Iain Small ${ }^{2}$, Monica Fletcher ${ }^{3}$, Tricia Bryant ${ }^{4}$ \\ ${ }^{1}$ Box Surgery, Box, Wiltshire, UK \\ 2 Peterhead Health Centre, Peterhead, Grampian, UK \\ 3 Education for Health, The Athenaeum, 10 Church Street, Warwick, UK \\ ${ }^{4}$ PCRS-UK, Smithy House, Waterbeck, Lockerbie, UK
}

Originally received 2nd January 2013; resubmitted 4th April 2013; revised 6th April 2013; accepted 12th April 2013; online 23rd August 2013

\begin{abstract}
In an attempt to improve the standards of primary respiratory care in the UK, the Primary Care Respiratory Society-UK (PCRS-UK), in conjunction with other leading respiratory-interested health professional and patient groups, has devised a General Practice Quality Award for Respiratory Medicine. The Award is divided into three modules separated into a total of seven clinical standards (in parentheses): 'Clinical' (prevention, early and accurate diagnosis, acute care, chronic care); 'Organisational' (equipment); and 'The Practice Team' (practice learning needs, educational strategy). Assessment is by submission of a written portfolio of 37 pieces of evidence including audit, reflective learning, patient feedback, and significant event analyses. The Award was piloted in five respiratory-interested practices across the UK. The practices reported improvements in practice organisation, practice teamwork, improved process measures such as improvement in quality of spirometry, and improved patient access to patient services. All practices in the UK are being invited to apply for the Award in 2013. It is hoped that it will provide a framework and stimulus for provision of high-quality primary respiratory care, not only in the UK, but also some aspects of the Award may be applicable on a wider international scale.

(C) 2013 Primary Care Respiratory Society UK. All rights reserved. K Gruffydd-Jones et al. Prim Care Respir J 2013; 22(3): 353-359 http://dx.doi.org/10.4104/pcrj.2013.00065
\end{abstract}

Keywords asthma, COPD, management, primary care, quality, standards

The full version of this paper, with online appendices,

is available online at www.thepcrj.org

\section{Background}

Against a global background of rising healthcare demands and constrained healthcare funding, it is imperative that the quality of healthcare provision is not diluted. In the UK the provision of highquality medical care has become a pivotal part of government health policy via the Quality, Improvement, Productivity and Prevention (QIPP) agenda ${ }^{1}$ and the National Health Service (NHS) Outcomes Framework 2010. ${ }^{2}$ The Department of Health (DH) Outcomes Strategy for People with COPD and Asthma ${ }^{3}$ and its companion document $t^{4}$ outline the aspirations for high-quality care in chronic obstructive pulmonary disease (COPD) and asthma. There is, however, evidence of suboptimal care including substantial variation in standards in COPD care across England, ${ }^{5}$ variation in the quality of primary care spirometry, ${ }^{6}$ and deficiencies in the assessment of the acute asthma attack. ${ }^{?}$

With this background in mind, a meeting of respiratoryinterested patient and health professional organisations led by the Primary Care Respiratory Society-UK (PCRS-UK) met in 2009 to discuss how to raise the quality of primary respiratory care. The decision was made to develop a Quality Award which would set out the standards that best define high-quality primary respiratory care and reward practices that met these standards (Box 1).

\section{Development process}

The Award design was devised and the development of the Award overseen by a multidisciplinary steering group composed of members from respiratory-interested health professionals and patient organisations (see Appendix 1, available online at www.thepcrj.org).

\footnotetext{
* Corresponding author: Dr Kevin Gruffydd-Jones, Box Surgery, Box, Wiltshire SN13 8NA, UK.

Tel: +44 (0)1225 742361 E-mail: Kevin.Gruffydd-Jones@gp-J83013.nhs.uk
} 


\section{Box 1. Aim of the PCRS-UK Practice Quality Award}

To set out the standards that best define high quality respiratory care in primary care, providing:

- Recognition of practices delivering a high standard of respiratory care

- A quality assurance mark for patients, commissioning groups and the wider NHS

- A developmental framework that can be used at practice, locality and national levels to promote, support and reward quality respiratory care in the primary care setting

The Quality Standards were initially developed by a multidisciplinary Module Development Group (see Appendix 2, available online at www.thepcrj.org). This group drew upon national respiratory guidelines to produce an initial set of standards and evidence requirements. ${ }^{3,8-13}$ This initial set was modified by a larger group using the following criteria: whether the standards were truly evidence-based; were practical and deliverable; were generalisable across a UK primary care population; and whether they were evaluable. The number of items of evidence was further reduced after consultation with seven primary care practices varying in size, geography, and socio-economics across the spectrum of UK general practice using the same criteria.

\section{Design and scope of the Award}

The Award has been partly based on the generic Royal College of General Practitioners Quality Practice Award (QPA) ${ }^{14}$ which assesses quality of care across a wide range of disease areas managed in general practice. QPA involves submission of a written portfolio of evidence across several modules, concentrating mainly on practice organisation.

The PCRS-UK Award is divided into three modules: 'Clinical', 'Organisation', and 'The Practice Team'. These are subdivided into seven standards as shown in Box 2.

\section{Box 2. Modules and Standards of the Quality Award}

- Clinical
o Prevention
o Early and accurate
diagnosis
o Acute care
o Chronic care

- Organisational

o Equipment

- The Practice Team

o Practice learning needs

o Educational strategy

The clinical standards are mainly centred on the disease areas of asthma and COPD, but examples of good practice in other areas of respiratory medicine can be submitted. The format of the standards has been modelled on that used by Health Improvement Scotland in their Asthma and COPD Services Clinical Standards. ${ }^{12,13}$ Each standard has a headline statement (e.g. "People listed on the asthma and COPD registers are offered regular structured review of their condition"), followed by the rationale for the statement and finally the evidence required to meet that standard. The full quality standards are shown in Figure 1.

Practices are asked to submit 37 pieces of written evidence within a 6-month period to the PCRS-UK assessors comprising audits, protocols, significant event analyses, patient case histories, and examples of reflective learning. Assessment of the written portfolio is carried out by two trained independent assessors drawn from the stakeholder organisations. A practice is required to provide all the evidence that it meets these standards in order to gain the PCRS-UK Quality Award.

\section{Piloting of the Award}

The Award was initially piloted in 2011 in five respiratory-interested practices in England and Scotland to establish whether working for the Award was feasible and to iron out any practical problems.

All phase 1 pilot practices successfully gained the Award. The practices reported that working for the Award had led to numerous improvements in practice organisation, varying from updating outdated protocols to actively involving all members of the practice team rather than respiratory care being carried out by one or two individuals.

As a result of the audit, there were significant improvements in some practices in the quality of spirometry, increased influenza vaccination uptake, and improved review of patients after hospital admission for acute COPD and asthma. The improvements were largely confined to process outcomes such as improved quality of care rather than outcome measures such as reduction in hospital admissions and exacerbations which were not recorded in this pilot phase. However, examples of tangible benefits from patients included improved access to surgery appointments for school children with asthma and improved access to smoking cessation services.

We also analysed qualitative feedback from these practices. Although practices acknowledged the need for extra time to complete the Award, feedback has been positive with comments such as "It has given us the opportunity to take time to really look at our respiratory service in detail ... and we're doing a good job" and "It was a motivating process and helped us engage the whole team".

The experience and feedback of the five pilot practices demonstrated that the PCRS-UK Quality Award is an important developmental opportunity for the whole practice and does drive improvements in care, even in high performing practices.

Following this initial pilot phase, minor adjustments to the original evidence requirements (such as examples of patient feedback questionnaires, suggested surveys and audits, and a more detailed practice profile) were made to the Award, which is being tested further in pilot phase 2 .

\section{Discussion}

Improvement in the quality of provision of healthcare has been a major priority in the UK and many healthcare systems throughout the world. The development and implementation of a Quality Award was seen by the stakeholder organisations as a method of incorporating the key elements of quality care improvement using Wagner's Chronic Care Model ${ }^{15}$ (improved organisation, improved health professional clinical care using education, and peer review) into a quality improvement method award that would be achievable in a wide range of primary care practices and raise standards of care. 

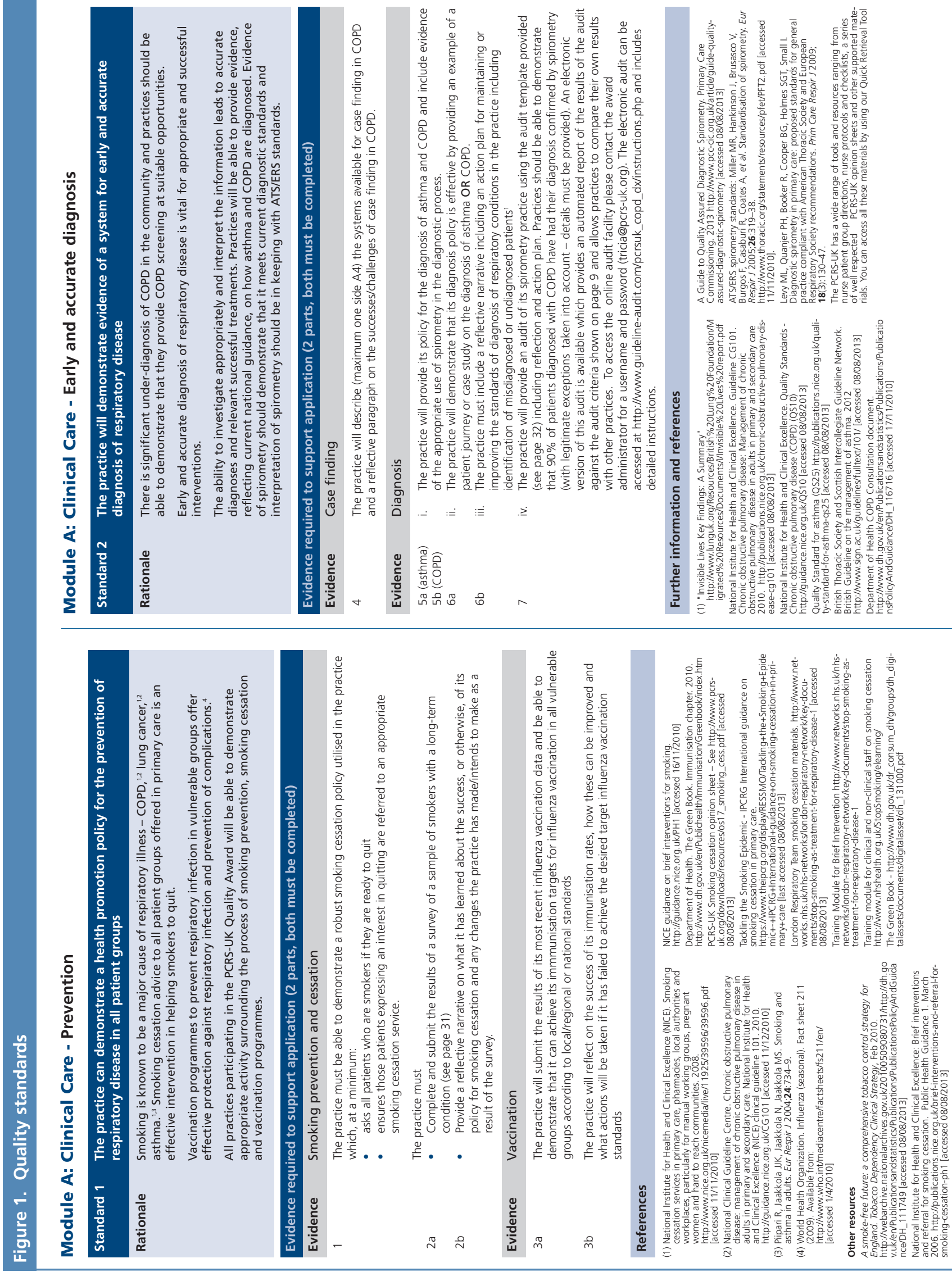

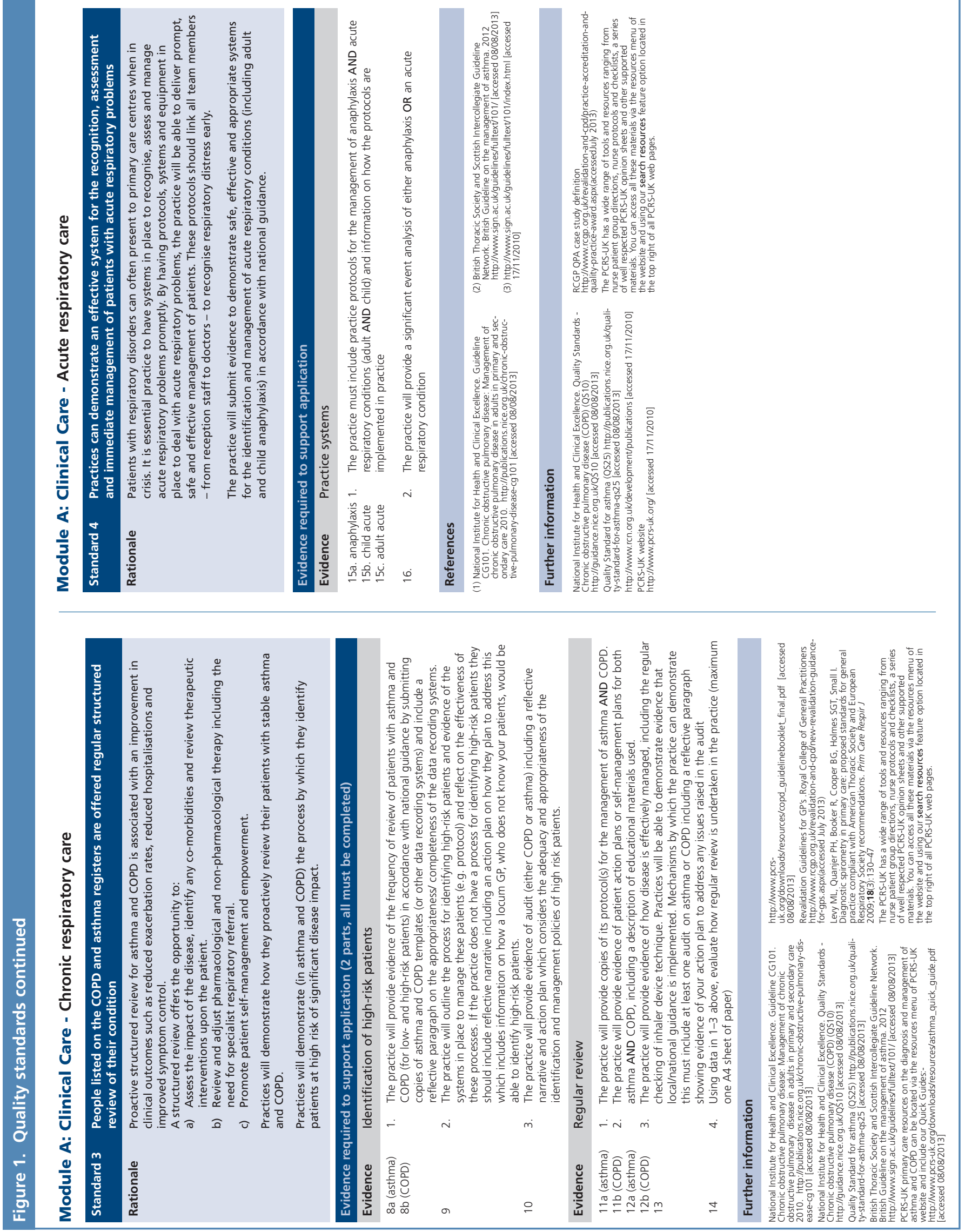

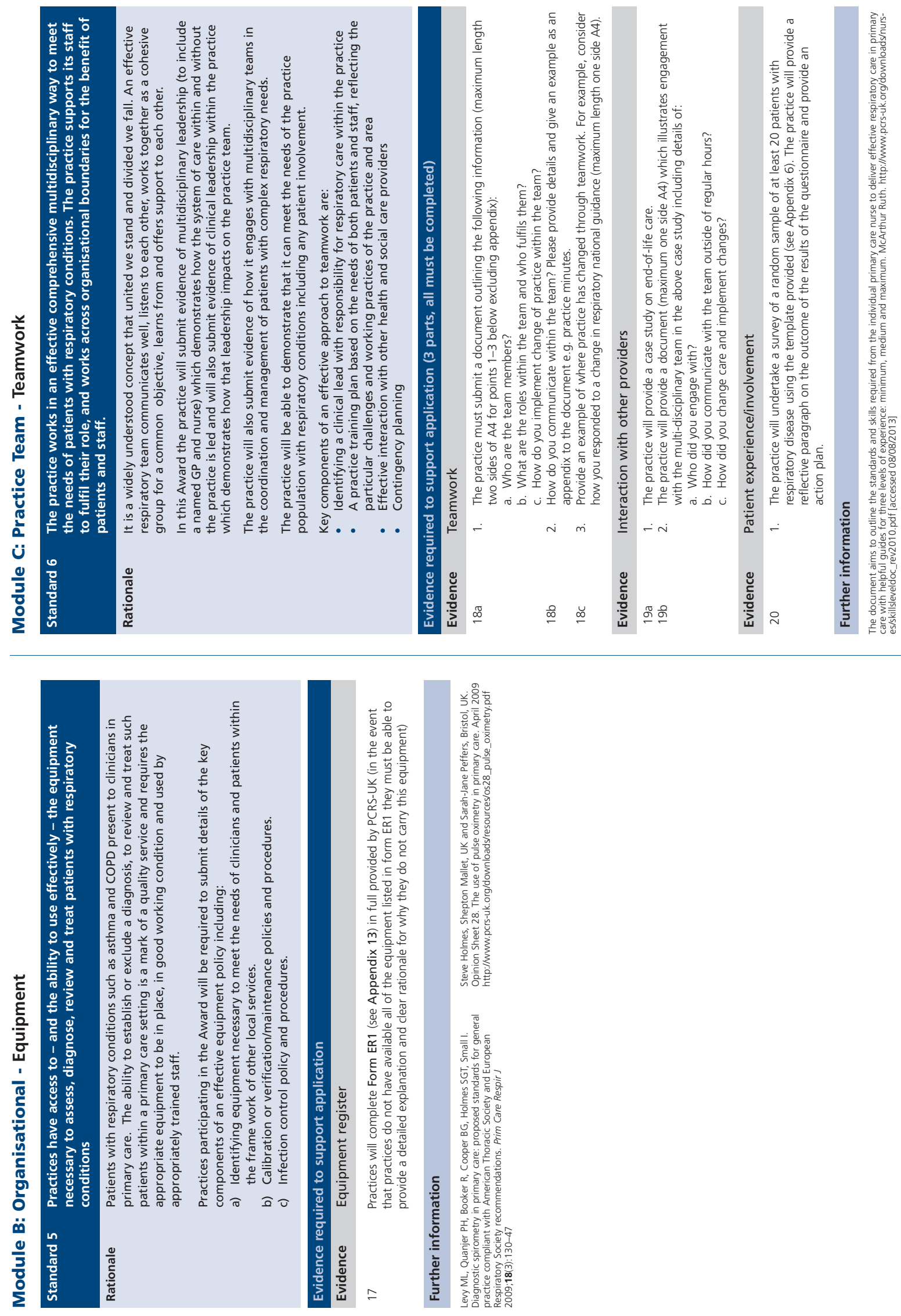


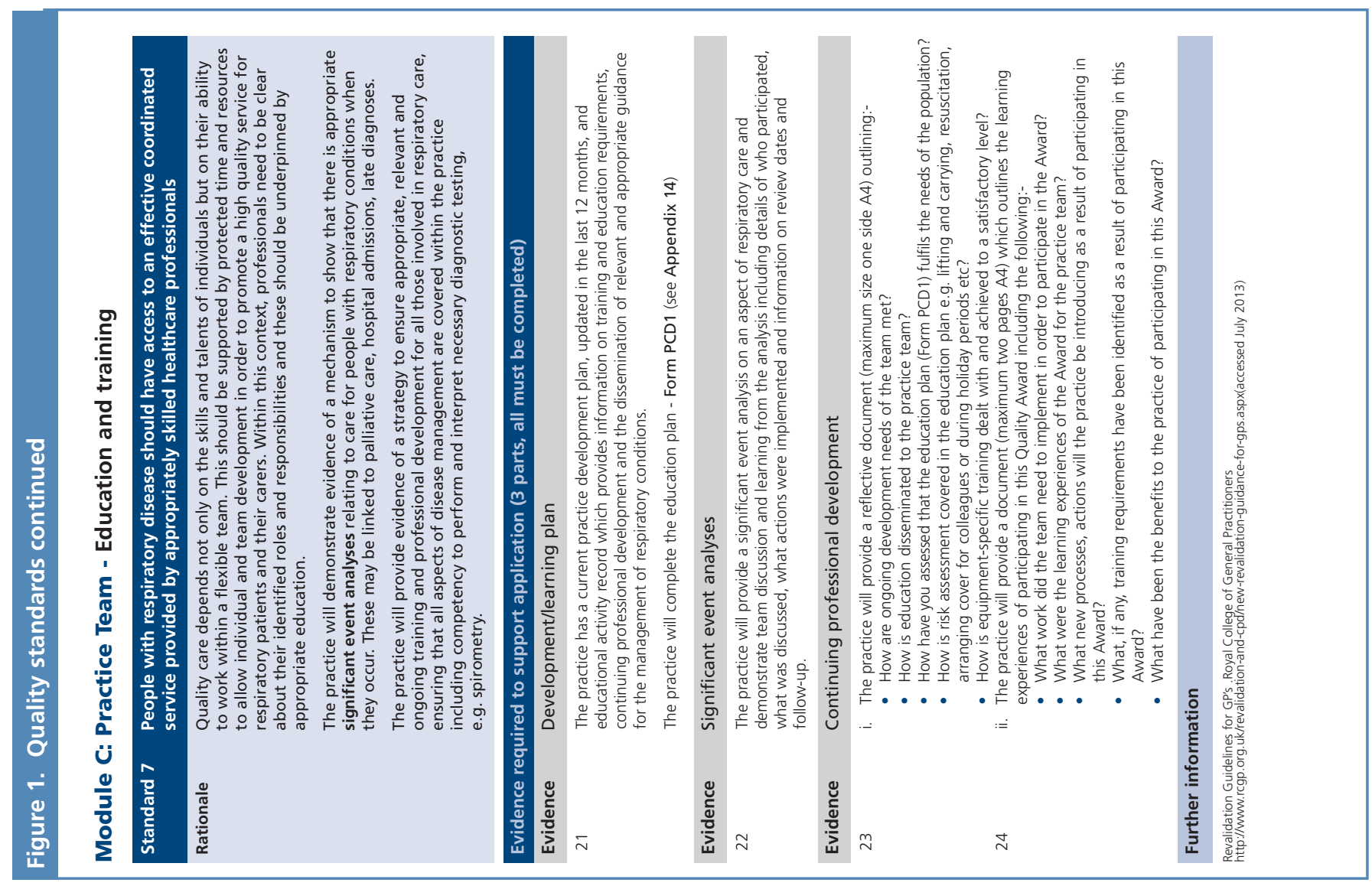

Although quality awards have been used to improve healthcare for several years, the evidence base for their efficacy is not large. The European Foundation for Quality Management ${ }^{16}$ has devised a model of healthcare quality improvement and Quality Award which has been adopted by many healthcare organisations in the Netherlands and Germany. However, a systematic review of performance based on this model showed only weak evidence of improvements. ${ }^{17}$ Surprisingly, there has only been limited evaluation of the UK Royal College of General Practitioners QPA which mainly focused on general practice organisation. ${ }^{4}$ A postal questionnaire sent to practices that had completed the QPA stated that there was an improvement in practice teamwork. ${ }^{18}$ In view of this limited evidence, it is important that this Respiratory Practice Award is properly evaluated when it is rolled out beyond the pilot stage.

The development of the PCRS-UK Quality Award involved the successful co-operation of respiratory-interested multi-professional and patient groups. During the iterative process the initial number of pieces of evidence required was reduced to minimise practice workload, and an important section added to include patient experience and practice feedback.

The feedback from the pilot practices suggested that there was a significant amount of work involved in collating the evidence needed for the Award. However, the impact of this increased workload could be greatly reduced by sharing the evidence submission with other members of the primary healthcare team. In return, there were tangible gains with regard to improved teamwork, patient access, and raised process standards (see "Piloting of the Award" section). This should be tempered by the fact that the pilot 1 practices were already respiratory-interested organisations. In addition, questions remain about long-term sustainability of the Award - for example, will improvements be maintained if key personnel leave the practice and will short-term process improvements translate into longer-term outcome benefits such as reduced patient admissions or improved patient quality of life?

It is planned to make the fully functional PCRS-UK Quality Award available to all general practices in the UK in 2013. As the Award is rolled out to a wider range of practices, there is a need to train more assessors. This is being met by training both lay and health professional assessors. A major challenge will be to encourage practices to apply for the Award. One possibility is to encourage groups of practices (e.g. Clinical Commissioning Groups in England) to apply for the Award to meet the UK Government's QIPP agenda using national or local financial incentives. Another possibility is to make individual modules available either as a precursor to carrying out the whole Award or as a quality improvement tool in its own right. Although developed for the UK, the standards would fit with most developed healthcare systems that rely on primary care for the diagnosis, treatment, and management of long-term conditions. It is acknowledged that some of the individual pieces of evidence might need to be changed to reflect local practice, although significant event analyses, reflection 
on multidisciplinary working, and completed audits are universally applicable.

\section{Conclusions}

The PCRS-UK Quality Award has been developed in conjunction with major professional and patient respiratory organisations in the UK. It offers a possible tool to provide a developmental framework that can be used at the practice, locality, and national level to promote high-quality respiratory medicine in primary care.

Further details of the Award can be found on the PCRS-UK website (http://www.pcrs-uk.org/pcrs-uk-quality-award).

\section{Handling editor Mike Thomas}

Acknowledgements In addition to all the work of the development committees, we would like to thank Inez Gentiles and Anne Smith for their hard work and commitment to this project.

Conflicts of interest KG-J has acted as consultant for and spoken on behalf of the Department of Health, GlaxoSmithKline, AstraZeneca, Almirall, Chiesi, Novartis, Boehringer Ingelheim, Mundipharma/NAPP, and Merck Sharp and Dohme. He is cochair of the Quality Award Group. IS is Chair of the Primary Care Respiratory Society Care-UK and co-chair of the Quality Award Development Group. He is a trustee of Asthma UK. MF has spoken for and acted as consultant for Almirall, Mundipharma/NAPP, and Novartis. TB is Director of Red Hot Irons Ltd. Red Hot Irons Ltd is contracted to provide the PCRS-UK Quality Award project management and operations services for the Primary Care Respiratory Society UK.

Contributorship Kevin Gruffydd-Jones is the principal author of this article, with significant contributions regarding methodology and input into the discussion from the other authors.

Funding The Quality Award development process and pilot process was kindly funded by unconditional educational grants from the following organisations: Allen \& Hanbury's (Respiratory Division of Glaxo Smith Kline), AstraZeneca UK Ltd, Boehringer Ingelheim Ltd, Chiesi Ltd, MSD UK, Napp Pharmaceuticals, Pfizer Ltd, Teva Ltd.

\section{References}

1. Department of Health. Quality Innovation, Productivity and Prevention (QIPP). www.dh.gov.uk/health/category/policy-ara/quality/qipp

2. Department of Health. NHS Outcome Framework 2011 to 2012. November 2010. http://www.dh.gov.uk/en/Publicationsandstatistics/Publications/PublicationsPolicyAn dGuidance/DH_122944

3. Department of Health. An Outcomes Strategy for People with Asthma and COPD. 2011. http://www.dh.gov.uk/en/Publicationsandstatistics/Publications/Publications PolicyAndGuidance/DH_127974
4. Department of Health. An Outcomes Strategy for COPD and Asthma: NHS Companion Document 2012. http://www.dh.gov.uk/en/Publicationsandstatistics/ Publications/PublicationsPolicyAndGuidance/DH_134000

5. Healthcare Commission. Clearing the Air: National Study of Chronic Obstructive Pulmonary Disease. 2006. http://archive.cqc.org.uk/_db/_documents/ COPD_report1_200607272728.pdf

6. Levy M, Quanjer PH, Booker R, Cooper BG, Holmes S, Small I. Diagnostic spirometry in primary care: proposed standards for general practice compliant with American Thoracic Society and European Respiratory Society recommendations. Prim Care Respir J 2009;18(3):130-47. http://dx.doi.org/10.4104/pcrj.2009.00054

7. Harrison B, Stephenson P, Mohan G, Nasser S. An ongoing confidential enquiry into asthma deaths in the Eastern Region of the United Kingdom 2001-2003. Prim Care Respir J 2005;14:303-13. http://dx.doi.org/10.1016/j.pcrj.2005.08.004

8. National Clinical Guideline Centre. Chronic Obstructive Pulmonary Disease: Management of Chronic Obstructive Pulmonary Disease in Adults in Primary and Secondary Care. http://www.nice.org.uk/nicemedia/live/13029/49425/49425.pdf

9. National Institute for Health and Clinical Excellence. Chronic Obstructive Pulmonary Disease (COPD) Quality Standard (QS10). http://www.nice.org.uk/guidance/ qualitystandards/chronicobstructivepulmonarydisease/copdqualitystandard.jsp

10. Healthcare Improvement Scotland. British Guideline on the Management of Asthma. May 2009 (revised 2012) http://www.brit-thoracic.org.uk/Portals/0/Guidelines/ AsthmaGuidelines/sign101\%20Jan\%202012.pdf

11. Department of Health. An Outcomes Strategy for People with Chronic Obstructive Pulmonary Disease (COPD) and Asthma in England. http://www.dh.gov.uk/en/ Publicationsandstatistics/Publications/PublicationsPolicyAndGuidance/DH_127974

12. Healthcare Improvement Scotland. Asthma Services for Children and Young People Clinical Standards. 2007. http://www.healthcareimprovementscotland.org/ previous_resources/standards/asthma_services_for_children_a.aspx

13. Healthcare Improvement Scotland. Chronic Obstructive Pulmonary Disease (COPD) Services - Clinical Standards and Evaluation. http://www. healthcareimprovementscotland. org/default.aspx?page $=11931$

14. Royal College of General Practitioners. Quality Practice Award (QPA). http://www.rcgp.org.uk/professional_development/team_quality/qpa.aspx

15. Wagner EH, Glasgow RE, Davis C, et al. Quality improvement in chronic illness care: a collaborative approach. Jt Comm J Qual Improv 2001;27:63-80.

16. Nabitz U, Klazinga N, Walburg J. The EFQM excellence model: European and Dutch experiences with the EFQM approach in health care. European Foundation for Quality Management. Int J Qual Health Care 2000;12(3):191-201. http://dx.doi.org/10.1093/intgh/12.3.191

17. Minkman $M$, Ahaus $K$, Huijsman R. Performance improvement based on integrated quality management models: what evidence do we have? A systematic literature review. Int I Qual Health Care 2007;19(2):90-104. http://dx.doi.org/10.1093/intghe/mzl071

18. McLean T, Atkins E, McLean K. Quality Award and teamworking: the perceptions of primary health care team members in Scotland. J Interprof Care 2005;19(2):149-55. http://dx.doi.org/10.1080/13561820400024084 
Appendix 1. Original Steering Committee and stakeholder organisations involved in developing the Quality Award

lain Small, Primary Care Respiratory Society-UK (PCRS-UK) (Co-Chair)

Kevin Gruffydd-Jones, PCRS-UK and Royal College of General Practitioners (RCGP) (Co-Chair)

Dr John Warwick, RCGP

Dr John O Kelly, Northern Ireland RCGP

Dr Steve Holmes, PCRS-UK

Dr Mark Hopkin, GP

Dr Tarek Bahkt, GP

Dr Raj Ramachandram, PCRS-UK

Dr Richard Russell, British Thoracic Society (BTS)

Dr Sheila Edwards, BTS

Dr Mike Morgan, BTS

Carol Stonham, PCRS-UK

Stephanie Wolfe, PCRS-UK

Bronwen Thomson, PCRS-UK

Monica Fletcher, Education for Health

Gill Hall, Respiratory Education UK

Dame Helena Shovelton, British Lung Foundation (BLF)

Kate Leach, BLF

Annette Duck, Association Respiratory Nurse Specialists (ARNS)

Simon Selo, Asthma UK

Neil Churchill, Asthma UK

\section{Current Quality Award Development Group}

Dr Noel Baxter, PCRS-UK

Monica Fletcher, Education for Health

Kevin Gruffydd-Jones, PCRS-UK

Gill Hall, Respiratory Education UK

Steve Holmes, PCRS-UK

Mark Hopkin, PCRS-UK

Matt Kearney, Department of Health

Chris Loveridge, Education for Health

Mike McKevitt, BLF

Richard Russell, BTS

Simon Selo, Asthma UK

lain Small, PCRS-UK

Carol Stonham, PCRS-UK

John Warwick, RCGP 
Appendix 2. Module Development Group

Kevin Gruffydd-Jones, PCRS-UK (Co-Chair Quality Award Development Group) and Royal College of General Practitioners (RCGP) lain Small, Primary Care Respiratory Society-UK (PCRS-UK) (Co-Chair Quality Award Development Group)

Mark Hopkin, GP, Stourbridge

Tarek Bakht, GP, Bolton

Steve Holmes, PCRS-UK Education Committee Chair and GP

Erica Haines, Specialist respiratory nurse, Buckinghamshire 